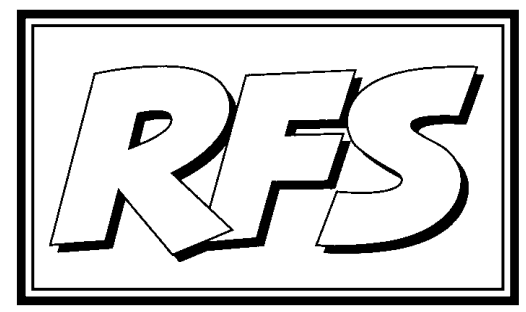

Revista de Fomento Social, 60 (2005), 87-112

\title{
La convergencia entre las comunidades autónomas españolas: una primera aproximación
}

— $M^{a}$ del Carmen LÓPEZ MARTÍN y Adolfo RODERO FRANGANILLO ${ }^{1}$ -

(Palabras clave: Comunidades Autónomas, Desigualdad regional, Política Regional, CONVERGENCIA, INDICADORES, REVISION BIBLIOGRAFFICA)

(KEY WORDS: AUTONOMOUS REGIONS, REGIONAL INEQUALITY, REGIONAL POLITICS,

CONVERGENCE, INDICATORS, BIBLIOGRAPHICAL RESEARCH)

1 Facultad de CC. EE. y Empresariales -ETEA- (Universidad de Córdoba). 


\section{Introducción}

La convergencia regional es un tema que aparece de forma muy frecuente en revistas, congresos, publicaciones universitarias, etc.

No vamos a detenernos en un planteamiento teórico del tema, ya que no es el objetivo de este trabajo ${ }^{2}$. Sólo quisiéramos recordar que son los modelos neoclásicos de crecimiento, aplicados al campo regional, los que defienden la convergencia entre regiones. Los supuestos de partida son la movilidad de los factores, la competencia perfecta y las funciones de producción equivalentes, lo cual nos lleva a los rendimientos decrecientes de los factores de producción ${ }^{3}$. También existen modelos teóricos que muestran la divergencia como un fenómeno general. En la obra de J. R. Cuadrado citada en la nota 3 , aparece una breve reseña de estos trabajos. Nuestro interés se fija en los estudios empíricos, en los que se recogen procesos de convergencia o divergencia.

El objetivo de este artículo es la determinación de si ha existido un proceso de convergencia entre las comunidades autónomas (CCAA) españolas, a partir de los trabajos publicados por los especialistas.

La metodología que hemos seguido para su elaboración ha consistido en la revisión de: $1^{\circ}$ ) las principales obras publicadas en España; $2^{\circ}$ ) algunas colecciones de revistas que recogen habitualmente escritos sobre el tema; y $3^{\circ}$ ) las aportaciones a varios Congresos o reuniones especializadas que han tratado con frecuencia este problema.

Con relación a la revisión llevada a cabo, es necesario realizar algunas observaciones aclaratorias: $1^{\circ}$ ) el período de revisión que hemos considerado abarca los trabajos que se han publicado en los ámbitos citados en un período reciente, en concreto, desde 1990 hasta la actualidad; $2^{\circ}$ ) aunque esta revisión está bastante adelantada, aún es posible añadir algunos títulos más; se trata, por tanto, de una primera versión de este trabajo; $3^{\circ}$ ) algunos trabajos tienen un contenido bastante amplio, en el que el análisis de la convergencia es sólo una parte; en general, las fichas que se han realizado

2 Esta cuestión puede analizarse en numerosas obras, aunque quizás la referencia básica sobre la misma es el artículo de BARRo y SALA i MARTín (1991) cuyo origen es la tesis doctoral de este último.

3 Una exposición esquemática de estas ideas se encuentra en J. CuAdRADO (1998), pág. 37 y siguientes. 
sobre los mismos se refieren al objetivo de nuestro trabajo, dejando de lado otros aspectos 4 .

Con relación a cada unos de los textos seleccionados hemos realizado, como ya se ha adelantado, una ficha en la que se resumen los aspectos más relevantes del trabajo en cuestión; en cada una de ellas se ha recogido el siguiente contenido: a) los objetivos del trabajo (en este apartado se ha tomado la finalidad general del texto en relación con la convergencia, el ámbito espacial que se ha considerado y el período temporal durante el que se ha estudiado esta cuestión); b) la metodología empleada (el tipo de análisis efectuado y las variables utilizadas para realizar dicho análisis); y c) las conclusiones obtenidas. Como no era posible, ni útil, incluir estas fichas en su totalidad, se ha elaborado un cuadro resumen en el que se recogen de forma esquemática todos los aspectos indicados. Este cuadro, que se incorpora a continuación, es el que ha servido como base para realizar el análisis que se incluye en el punto siguiente. A partir de todo este material, el cual se ha sistematizado y ordenado, se han elaborado unas conclusiones fundadas.

En consecuencia, el contenido de este texto se estructura en los siguientes términos: $1^{\circ}$ ) esta introducción, en la que a continuación se incluye el cuadro resumen que sintetiza la información manejada; $2^{\circ}$ ) el análisis de los textos revisados (distinguiendo los objetivos de los trabajos analizados y la metodología de los mismos); $3^{\circ}$ ) nuestras conclusiones, a partir lógicamente de los análisis ajenos; y $4^{\circ}$ ) las referencias bibliográficas completas de los textos estudiados.

4 En algunos títulos se realiza una revisión de estudios empíricos sobre la convergencia regional (en general); por ejmplo: C. GIL (2001), p.43 y F. J. GoERLICH y M. MAS (2001), pp. 55-56. 


\begin{tabular}{|c|c|c|c|c|c|c|c|}
\hline 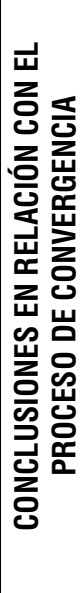 & 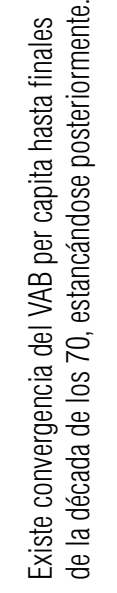 & 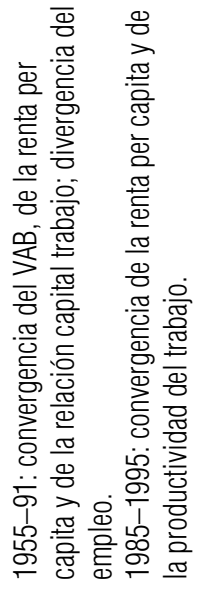 & 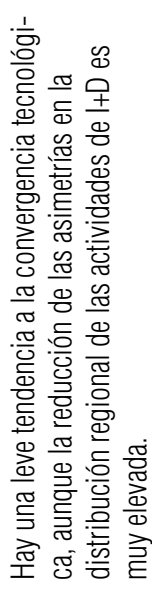 & 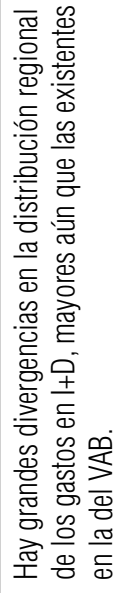 & 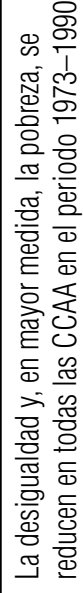 & 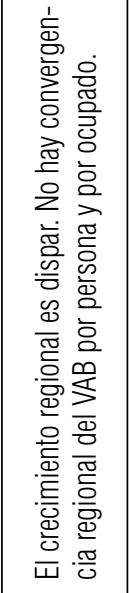 & 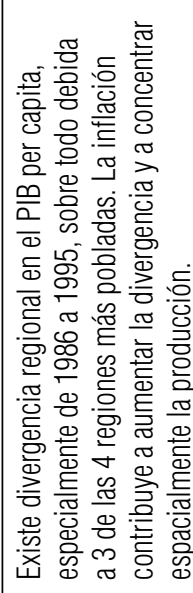 \\
\hline 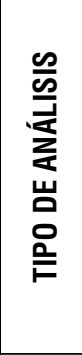 & 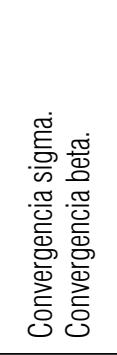 & 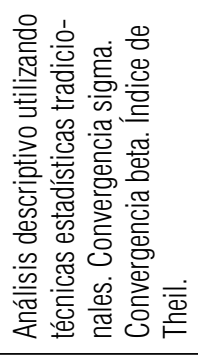 & 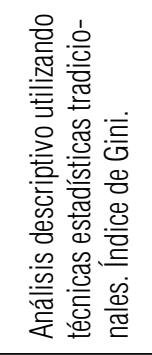 & 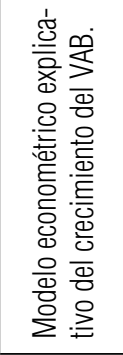 & 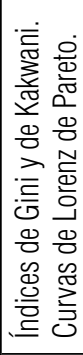 & 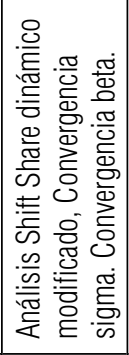 & 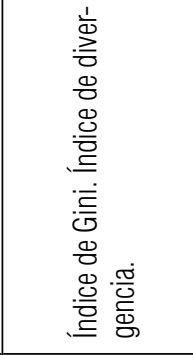 \\
\hline $\begin{array}{l}\text { 음 } \\
\text { 음 } \\
\text { 똠 }\end{array}$ & 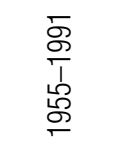 & 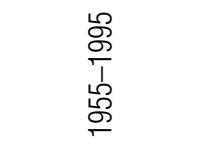 & $\begin{array}{l}\text { 요 } \\
\frac{1}{1} \\
\stackrel{8}{0} \\
\text { O }\end{array}$ & 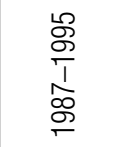 & $\begin{array}{l}\frac{8}{0} \\
\frac{1}{1} \\
\frac{\pi}{\square}\end{array}$ & $\begin{array}{l}\stackrel{2}{\circ} \\
\frac{\pi}{1} \\
\infty \\
\stackrel{0}{\square}\end{array}$ & 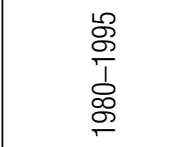 \\
\hline $\begin{array}{l}\text { 号 } \\
\text { 产 } \\
\text { 品 }\end{array}$ & 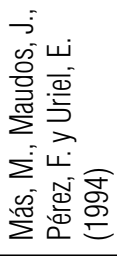 & 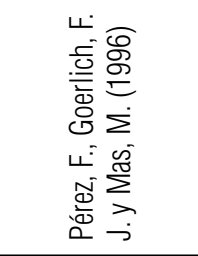 & 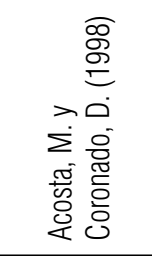 & 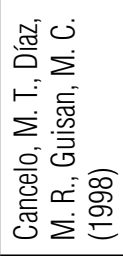 & 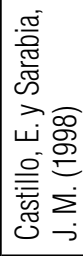 & 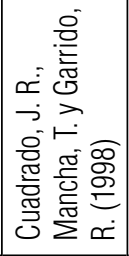 & 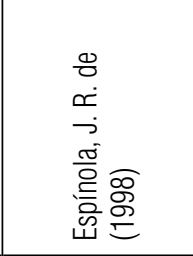 \\
\hline 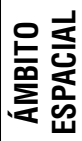 & \multicolumn{7}{|c|}{ 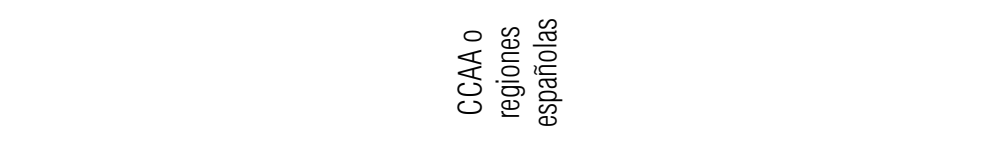 } \\
\hline
\end{tabular}




\begin{tabular}{|c|c|c|c|c|c|c|c|}
\hline 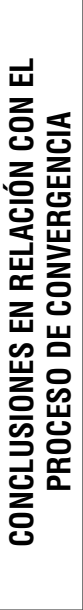 & 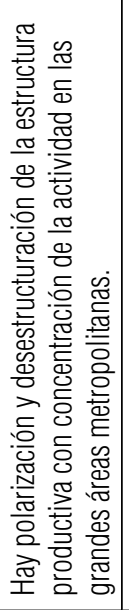 & 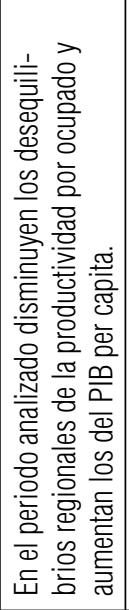 & 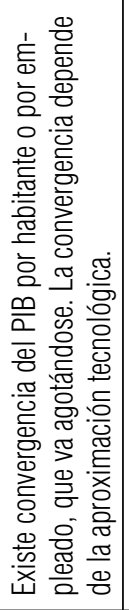 & 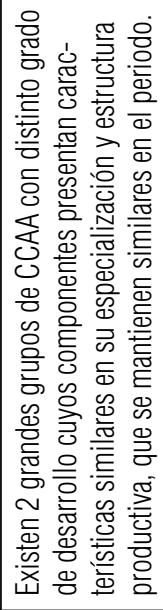 & 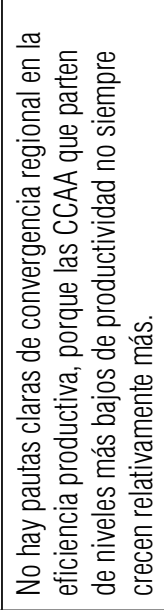 & 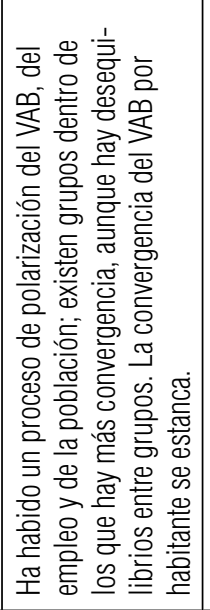 & 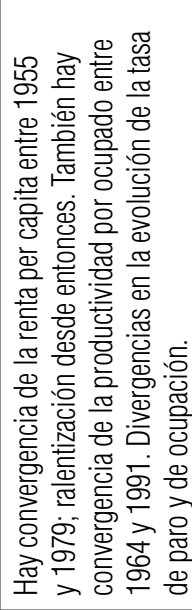 \\
\hline 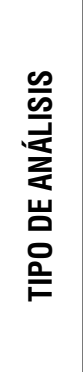 & 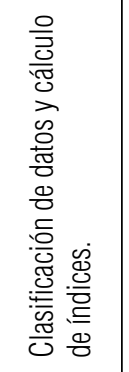 & 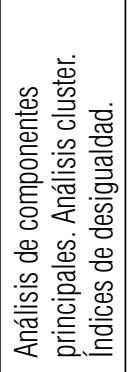 & 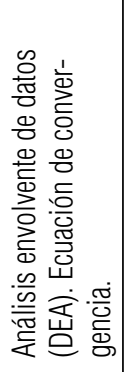 & 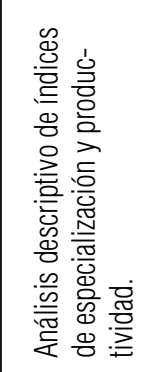 & 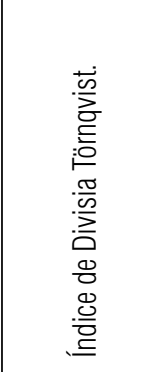 & 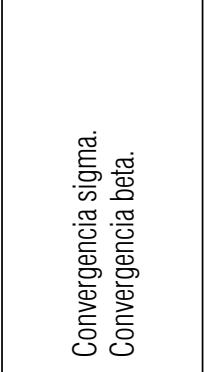 & 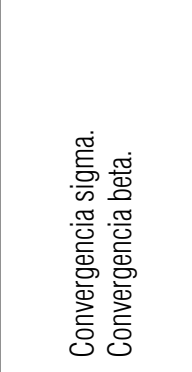 \\
\hline $\begin{array}{l}\text { 옴 } \\
\text { 음 } \\
\text { 乩 }\end{array}$ & 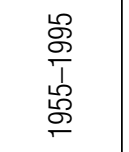 & $\begin{array}{l}\infty \\
\mathscr{O} \\
\bar{\sigma} \\
\infty \\
\infty \\
O \\
\end{array}$ & $\begin{array}{l}\frac{5}{8} \\
\frac{1}{1} \\
\frac{8}{6} \\
\frac{5}{5}\end{array}$ & $\frac{\mathscr{9}}{\frac{1}{1}}$ & $\begin{array}{l}\frac{5}{0} \\
\frac{1}{1} \\
\frac{6}{5} \\
\text { के }\end{array}$ & $\begin{array}{l}\stackrel{2}{\circ} \\
\frac{1}{1} \\
\infty \\
0 \\
\end{array}$ & $\begin{array}{l}\infty \\
\frac{8}{0} \\
\frac{1}{1} \\
\stackrel{0}{0} \\
\end{array}$ \\
\hline $\begin{array}{l}\text { 足 } \\
\text { 品 } \\
\text { 品 }\end{array}$ & 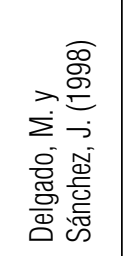 & 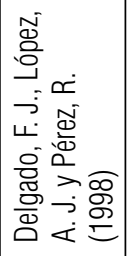 & 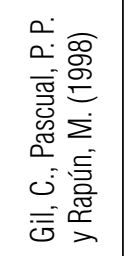 & 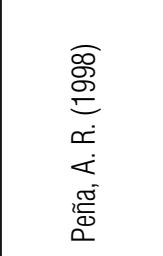 & 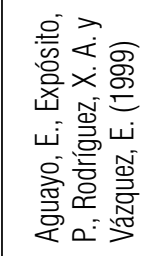 & 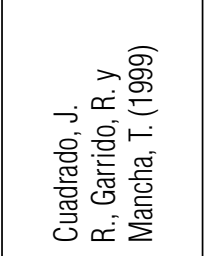 & 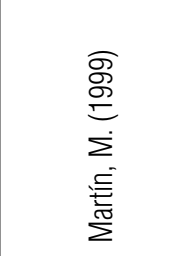 \\
\hline 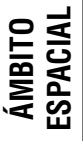 & \multicolumn{7}{|c|}{ 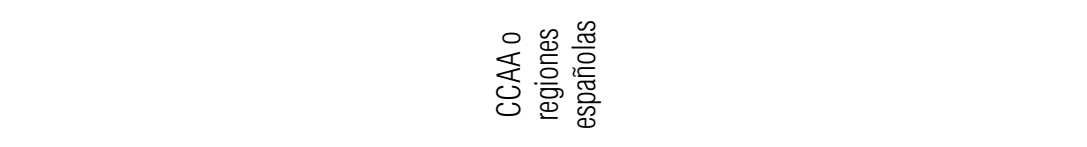 } \\
\hline
\end{tabular}




\begin{tabular}{|c|c|c|c|c|c|c|}
\hline 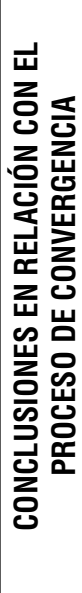 & 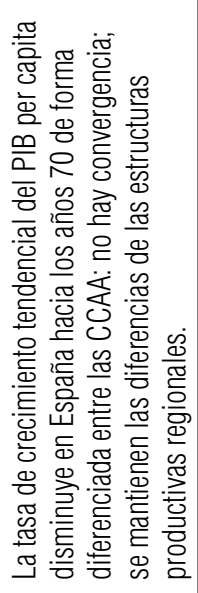 & 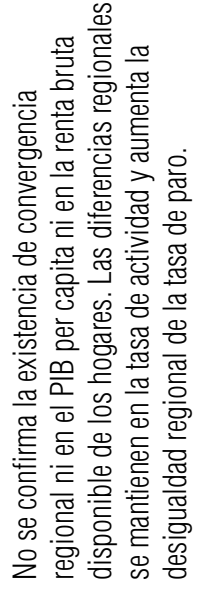 & 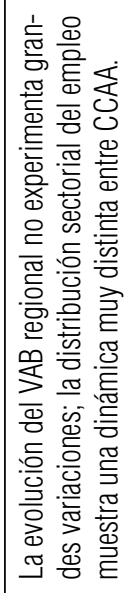 & 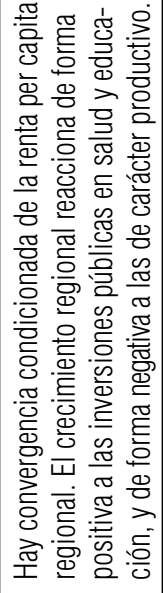 & 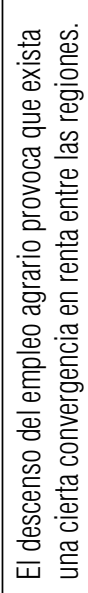 & 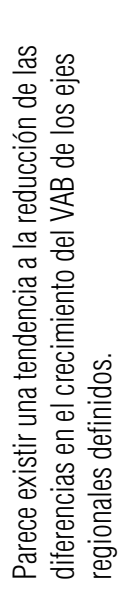 \\
\hline 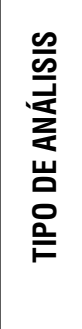 & 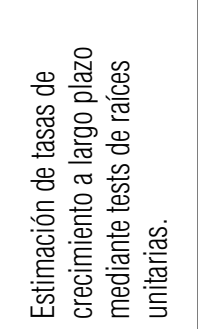 & 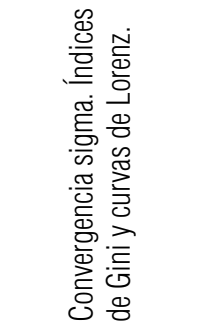 & 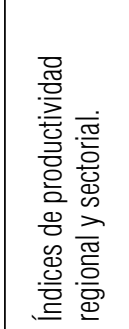 & 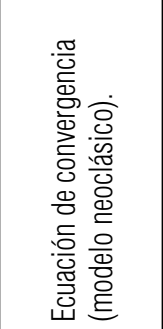 & 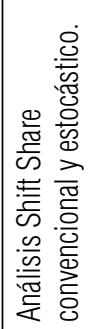 & 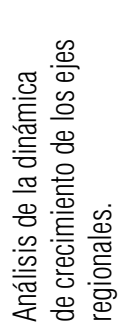 \\
\hline $\begin{array}{l}\text { 옹 } \\
\text { 음 } \\
\text { 뜸 }\end{array}$ & 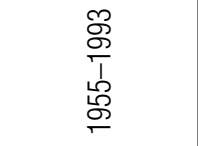 & $\begin{array}{l}\text { 요 } \\
\frac{0}{1} \\
\frac{1}{0} \\
\text { O }\end{array}$ & $\begin{array}{l}\infty \\
\frac{0}{0} \\
\frac{1}{1} \\
\text { 욤 }\end{array}$ & 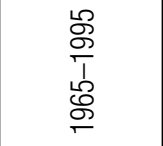 & $\begin{array}{l}8 \\
\varnothing \\
1 \\
0 \\
0 \\
0\end{array}$ & $\begin{array}{l}\text { ণิ } \\
\stackrel{1}{1} \\
\frac{1}{\infty} \\
\text { o }\end{array}$ \\
\hline 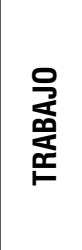 & 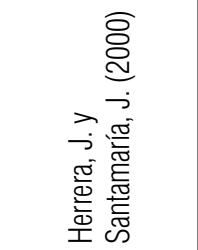 & 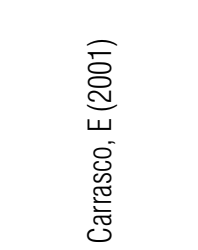 & 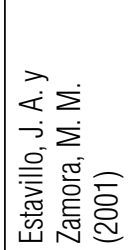 & 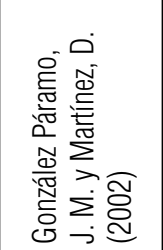 & 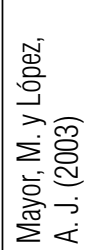 & 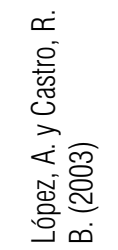 \\
\hline 을 & \multicolumn{6}{|c|}{ 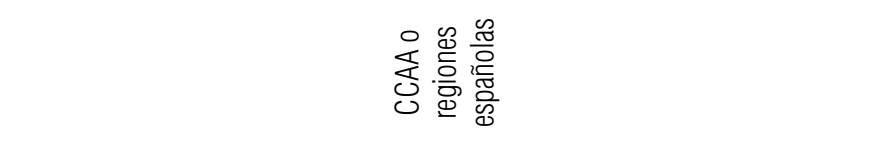 } \\
\hline
\end{tabular}




\begin{tabular}{|c|c|c|c|c|c|c|}
\hline 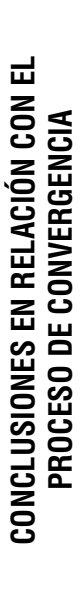 & 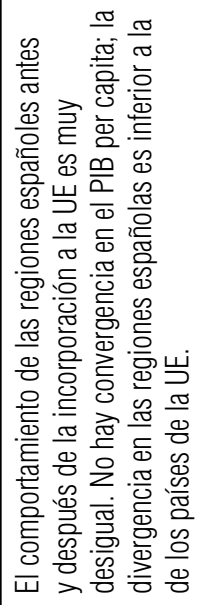 & 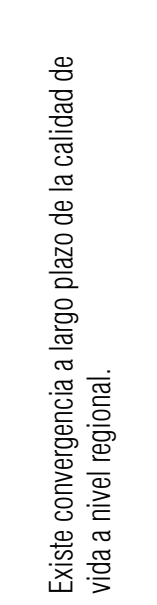 & 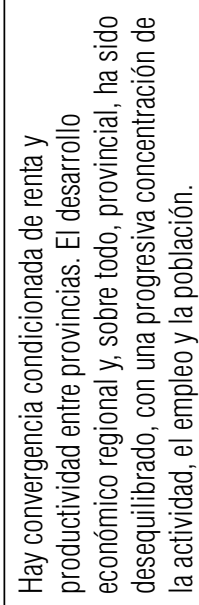 & 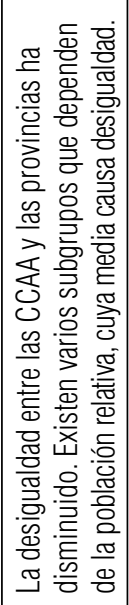 & 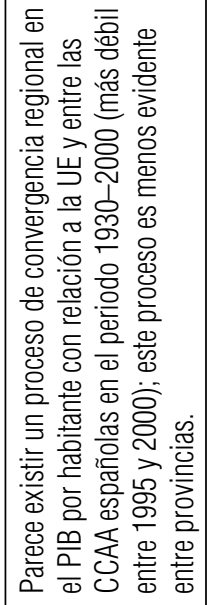 & 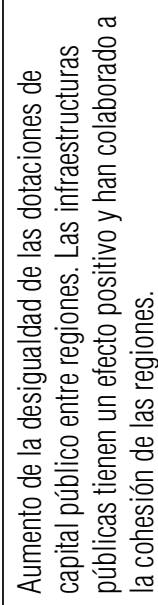 \\
\hline 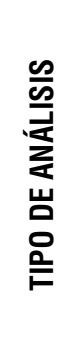 & 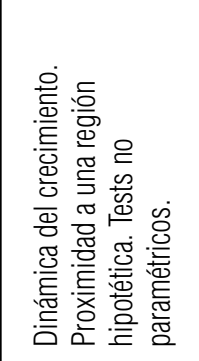 & 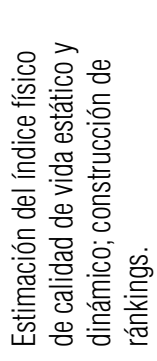 & 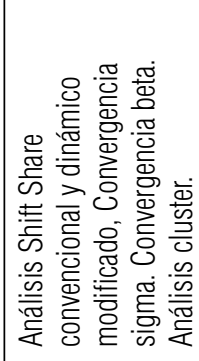 & 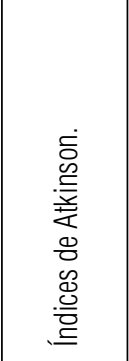 & 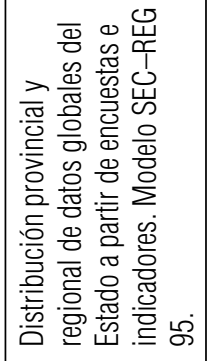 & 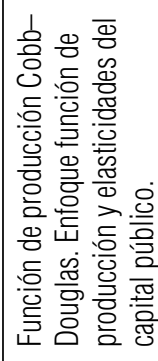 \\
\hline $\begin{array}{l}\text { 옹 } \\
\text { 음 } \\
\text { 岁 }\end{array}$ & $\begin{array}{l}\text { 요 } \\
\frac{9}{1} \\
\frac{1}{8} \\
0 \\
\end{array}$ & $\begin{array}{l}\frac{8}{0} \\
\frac{8}{8} \\
\frac{8}{1}\end{array}$ & 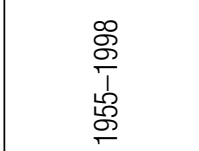 & 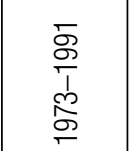 & $\begin{array}{l}\text { ஜ } \\
\text { సे } \\
\text { ర్ల }\end{array}$ & 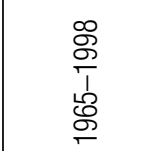 \\
\hline 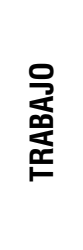 & 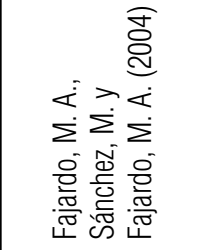 & 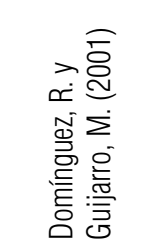 & 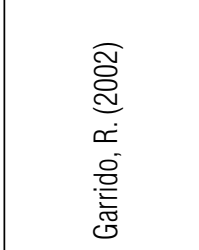 & 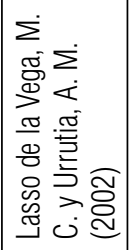 & 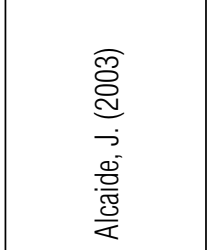 & 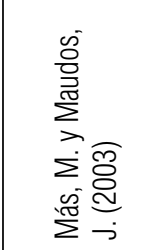 \\
\hline 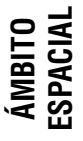 & 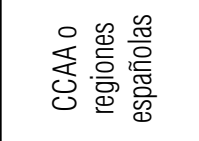 & & & 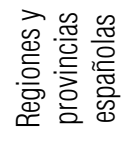 & & \\
\hline
\end{tabular}




\begin{tabular}{|c|c|c|c|c|c|}
\hline 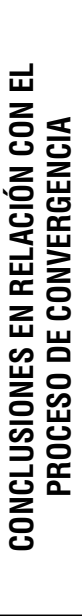 & 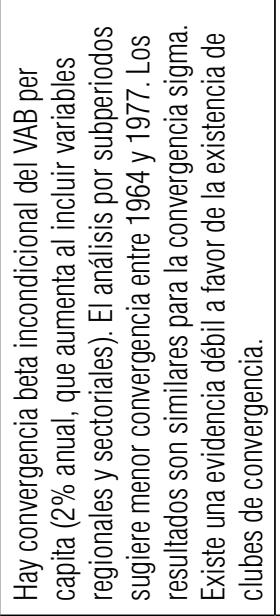 & 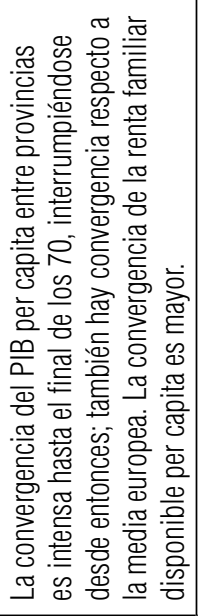 & 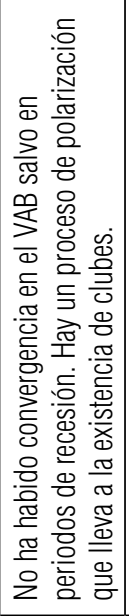 & 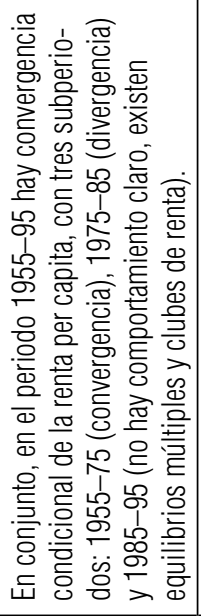 & 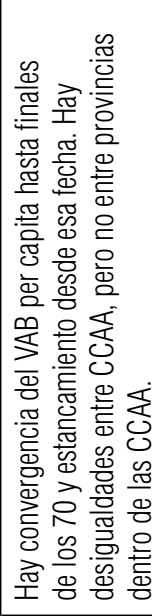 \\
\hline 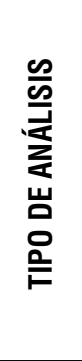 & 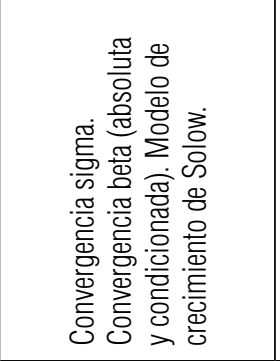 & 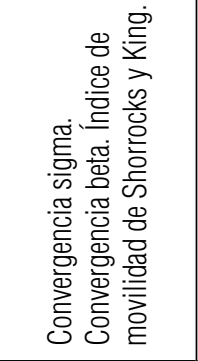 & 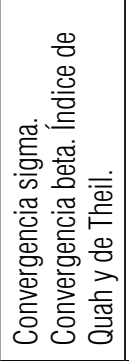 & 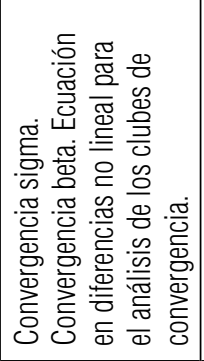 & 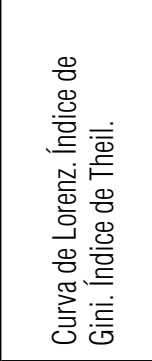 \\
\hline $\begin{array}{l}\text { 옴 } \\
\text { 움 } \\
\text { 는 }\end{array}$ & 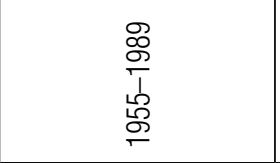 & 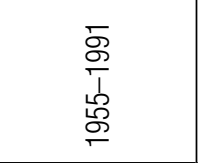 & 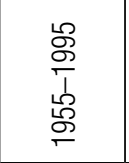 & 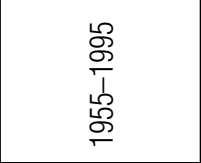 & 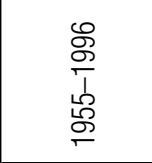 \\
\hline 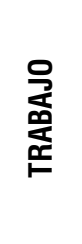 & 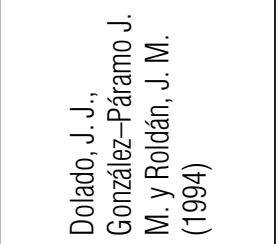 & 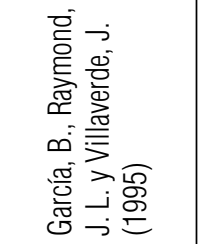 & 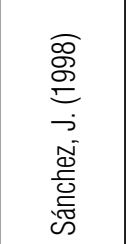 & 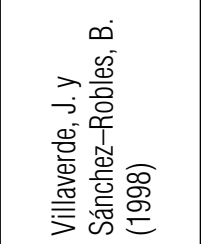 & 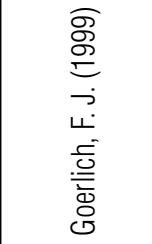 \\
\hline 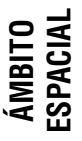 & \multicolumn{5}{|c|}{ 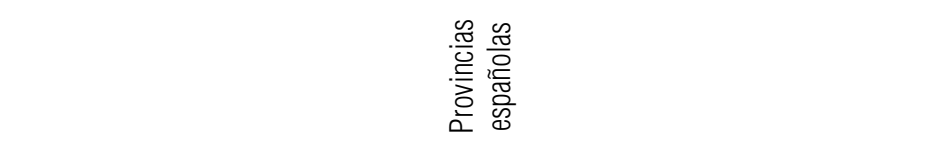 } \\
\hline
\end{tabular}




\begin{tabular}{|c|c|c|c|c|c|c|c|}
\hline 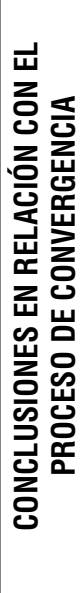 & 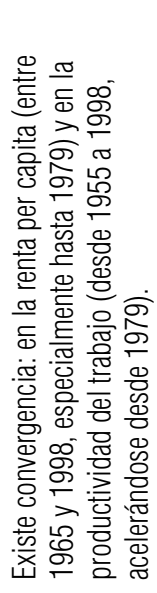 & 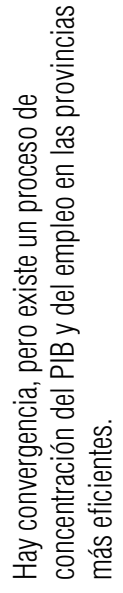 & 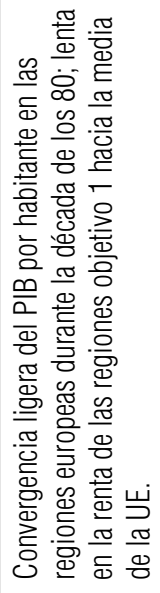 & 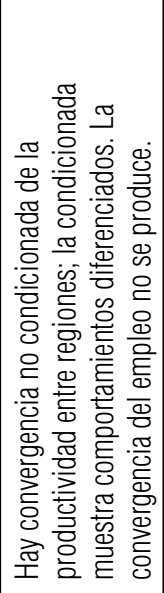 & 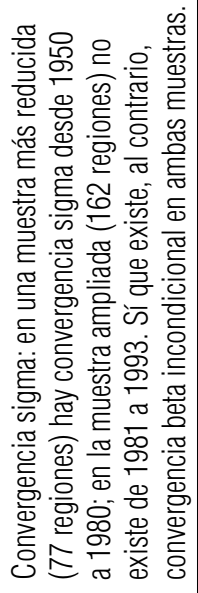 & 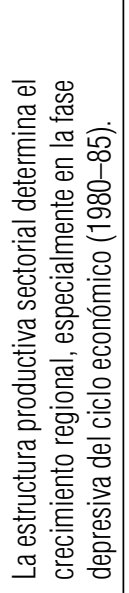 & 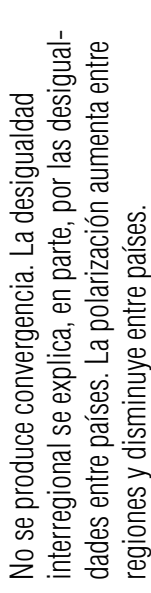 \\
\hline 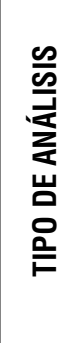 & 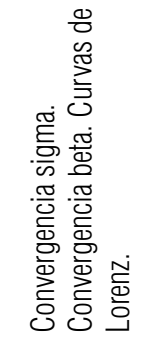 & 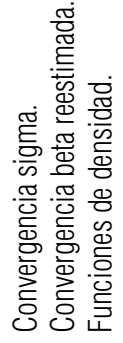 & 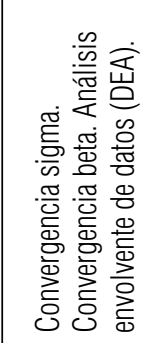 & 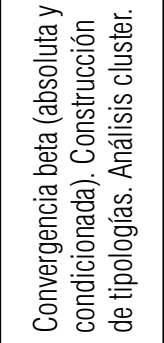 & 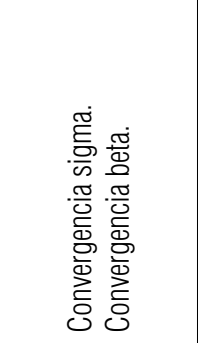 & 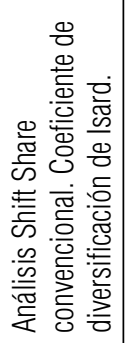 & 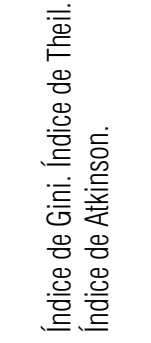 \\
\hline $\begin{array}{l}\text { 옹 } \\
\text { 음 } \\
\text { 똠 }\end{array}$ & 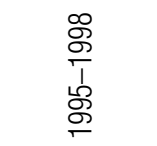 & 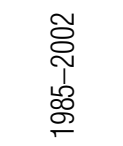 & 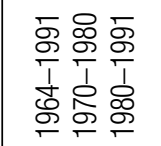 & $\frac{\mathscr{m}}{\frac{\pi}{1}}$ & 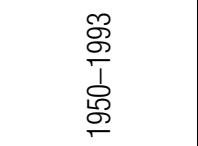 & $\begin{array}{l}\frac{8}{8} \\
\frac{1}{1} \\
\text { ᄋ } \\
\frac{0}{1}\end{array}$ & $\begin{array}{l}\frac{8}{\infty} \\
\frac{1}{1} \\
\frac{1}{\infty} \\
\frac{9}{1}\end{array}$ \\
\hline 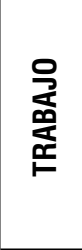 & 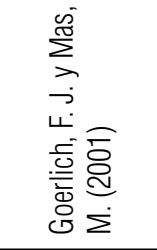 & 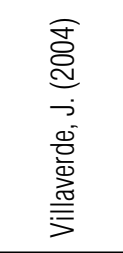 & 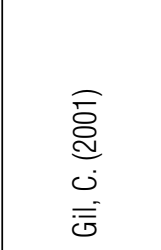 & 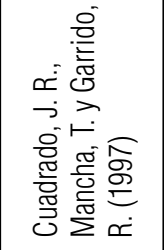 & 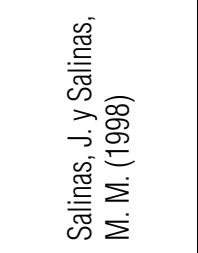 & 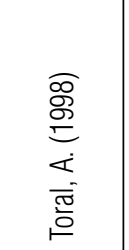 & 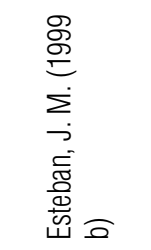 \\
\hline 은 & \multicolumn{2}{|c|}{ 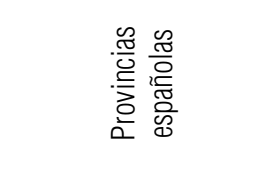 } & 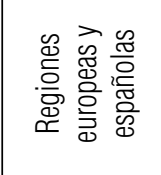 & 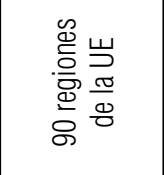 & 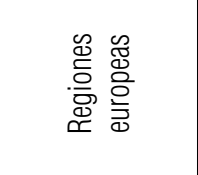 & 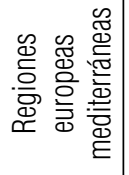 & 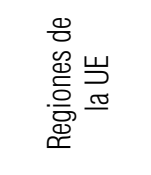 \\
\hline
\end{tabular}




\begin{tabular}{|c|c|c|c|c|c|c|}
\hline 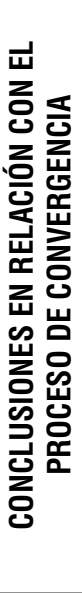 & 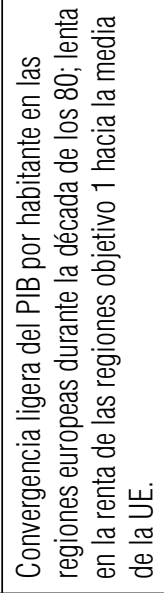 & 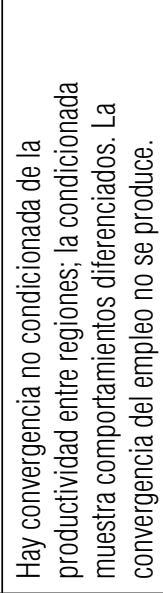 & 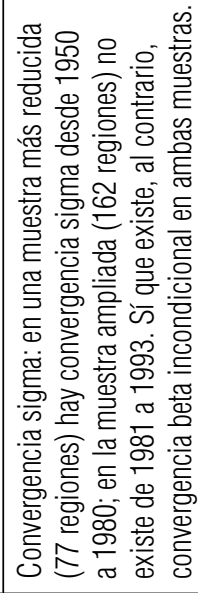 & 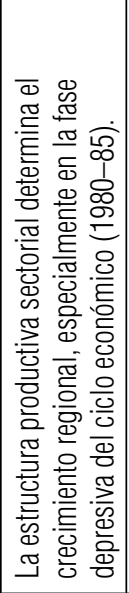 & 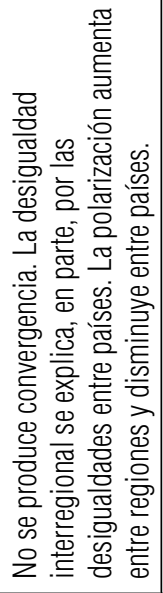 & 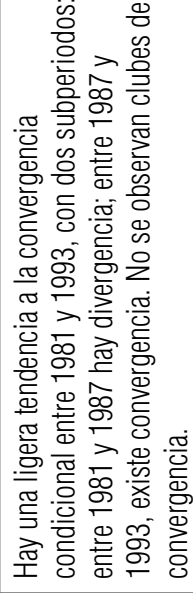 \\
\hline 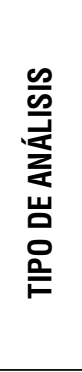 & 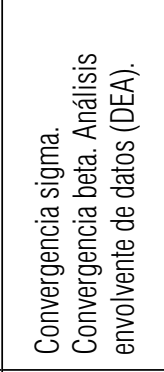 & 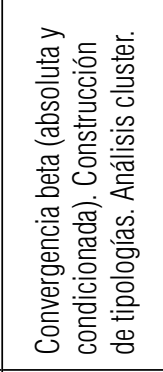 & 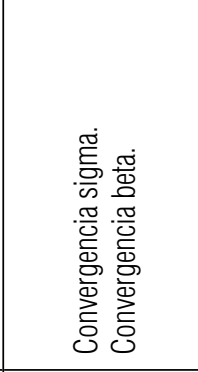 & 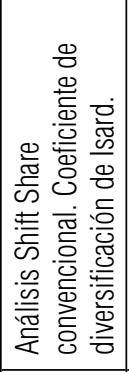 & 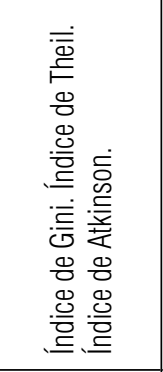 & 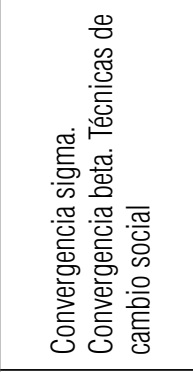 \\
\hline $\begin{array}{l}\text { 옴 } \\
\text { 음 } \\
\text { 뗨 }\end{array}$ & 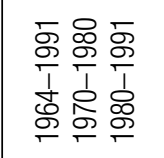 & $\frac{\mathscr{\%}}{\frac{\mathscr{O}}{1}}$ & 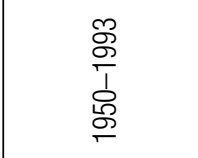 & $\begin{array}{l}\text { 8 } \\
\frac{0}{1} \\
\stackrel{1}{\circ} \\
\text { ᄋ }\end{array}$ & $\begin{array}{l}\frac{9}{0} \\
\frac{0}{1} \\
\frac{1}{\infty} \\
\frac{0}{1}\end{array}$ & 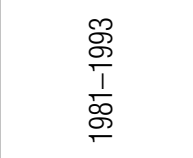 \\
\hline 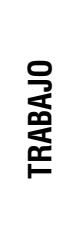 & $\begin{array}{l}\widehat{\bar{\delta}} \\
\dot{d} \\
\dot{0} \\
\dot{\bar{j}}\end{array}$ & 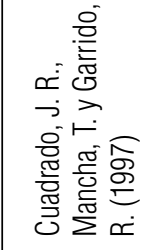 & 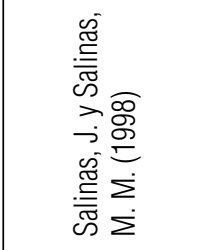 & 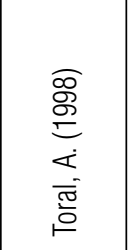 & 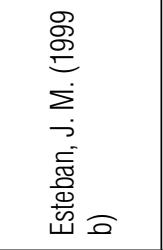 & 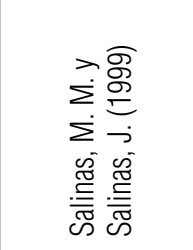 \\
\hline 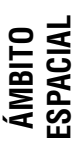 & 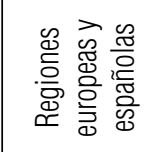 & 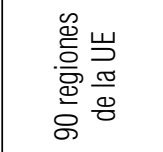 & 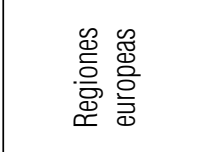 & 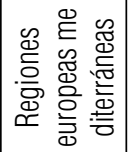 & 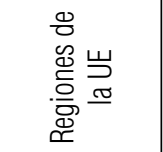 & 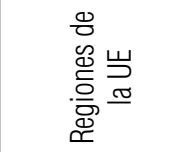 \\
\hline
\end{tabular}




\begin{tabular}{|c|c|c|c|c|c|}
\hline 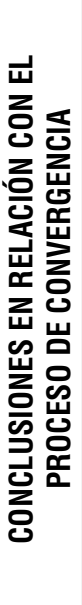 & 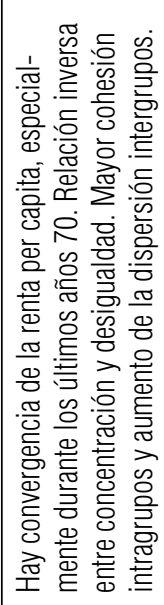 & 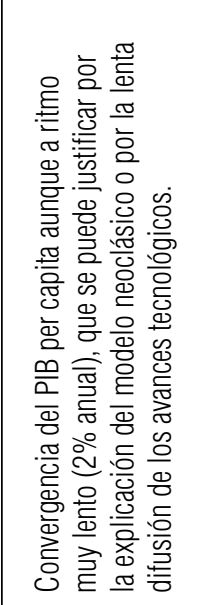 & 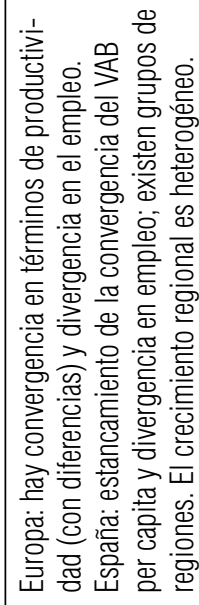 & 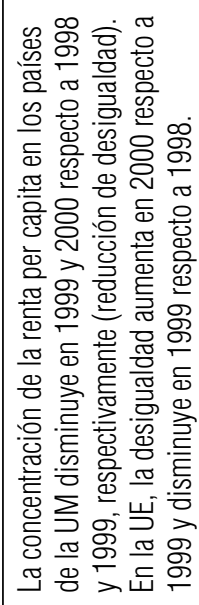 & 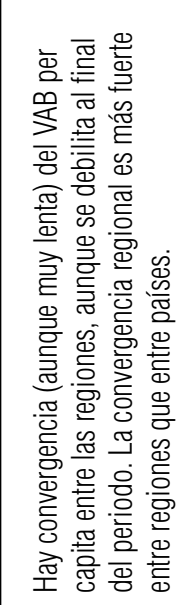 \\
\hline 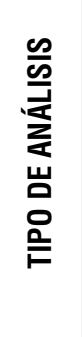 & 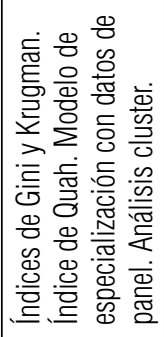 & 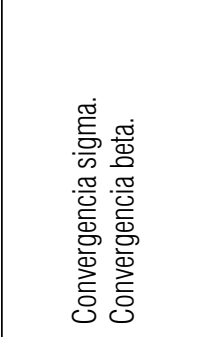 & 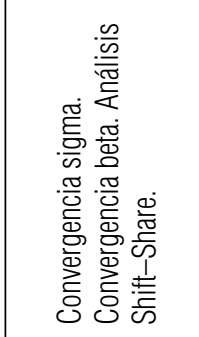 & 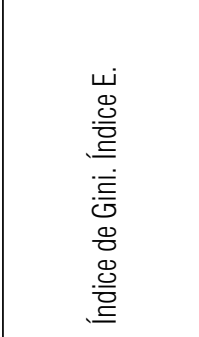 & 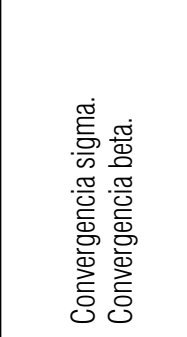 \\
\hline $\begin{array}{l}\text { 음 } \\
\text { 음 } \\
\text { 똠 }\end{array}$ & 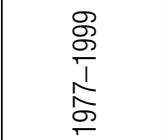 & 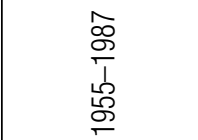 & $\begin{array}{l}\text { 요 } \\
\frac{D}{1} \\
\infty \\
\infty \\
\end{array}$ & 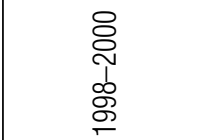 & 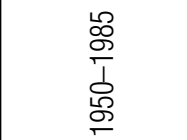 \\
\hline 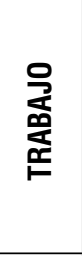 & 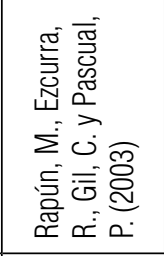 & 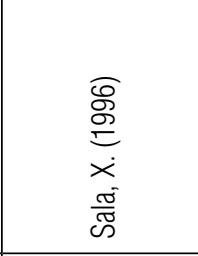 & 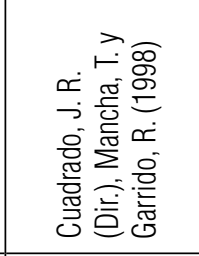 & 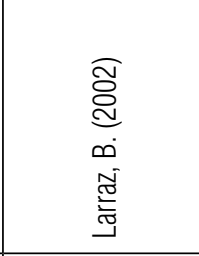 & 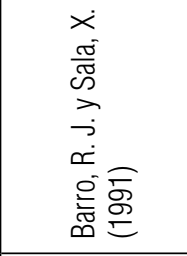 \\
\hline 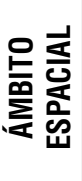 & 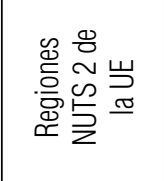 & 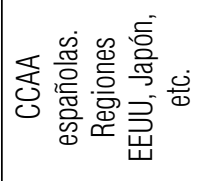 & 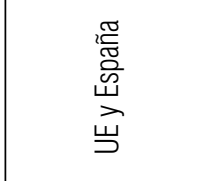 & 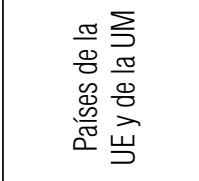 & 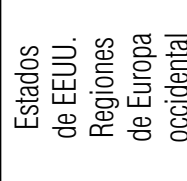 \\
\hline
\end{tabular}




\section{Análisis de los textos revisados}

\subsection{Objetivos}

Puesto que el objetivo de este trabajo ha sido la comprobación de si existe convergencia o divergencia regional, en todos los textos analizados aparece precisamente dicho objetivo aplicado a las regiones o provincias. Es el resultado obvio de la selección realizada. Ello no impide, evidentemente, que haya otros estudios que se centran en los problemas del desarrollo regional desde otros puntos de vista.

Por otra parte, aparecen análisis con contenidos más complejos, en los que además de la posible convergencia, se investigan otros aspectos (causas que determinan el desarrollo, aspectos sectoriales, etc.); en estos casos, nos hemos centrado en el objetivo que queríamos investigar, dejando a un lado, casi siempre, las demás cuestiones.

Una de las observaciones que se pueden realizar como resultado de la revisión, es que el número de trabajos es muy elevado -a pesar de que la revisión no ha sido exhaustiva-, lo que demuestra que estamos ante uno de los temas centrales de la economía regional. En este sentido, convendría hacer una matización: aunque es un tema que ha preocupado a los especialistas desde los años sesenta y aun antes, es a partir de los escritos de Barro y Sala ${ }^{5}$, en los primeros años noventa, cuando los investigadores españoles publican numerosos trabajos en esta línea. Sin embargo, a finales de la década, parece que la aplicación de las técnicas habituales (convergencia beta y convergencia sigma, principalmente) se encuentra ya algo agotada; quizás por ello, en los primeros años del siglo actual, los trabajos se han ido dirigiendo a otras cuestiones que tratan de explicar las causas, las características, los efectos del desarrollo regional, yendo más allá de la mera contrastación de la convergencia o divergencia, en su caso.

$\mathrm{Si}$ atendemos al ámbito espacial, el contenido de los estudios es muy variado: las provincias españolas, las comunidades autónomas o regiones españolas, las regiones de la Unión Europea (UE) o parte de ellas, las regiones

5 Además del artículo de 1991 y los otros textos indicados en la bibliografía, son referencias básicas de estos autores, los trabajos de 1992 y 1995 (BARRO y SALA (1992), "Convergence", Journal of Political Economy, vol. 100, pp. 223-251 y SALA (1995), Economic Growth, Nueva York, Edit. McGraw Hill). 
de algunos países europeos, e incluso las regiones (estados, etc.) de otros países no europeos (Estados Unidos, Japón, etc.). Aunque hemos revisado todos ellos, nuestra meta, como se recoge en el propio título del artículo, han sido las CCAA españolas, lo que reduce sensiblemente el número de textos que la tratan.

Esto plantea un problema delicado. El Estado español de las autonomías tiene su origen en la Constitución de 1978; estamos hablando de un período de unos 25 años. Anteriormente, la organización territorial del Estado se centraba en las provincias y en algunos escasos aspectos en una cierta regionalización. Por tanto ¿tiene sentido analizar el comportamiento de las CCAA desde, por ejemplo, 1955, si en esos años no existía esta organización territorial? Si en estos años aparece un proceso convergente o divergente ¿se puede interpretar como resultado de un comportamiento regional o más bien como resultado de la evolución de las provincias, relacionado quizás con un fenómeno de difusión del desarrollo, en su caso?

El aspecto temporal también muestra una diversificación de los estudios considerados. Muchos de ellos toman un largo periodo que va, normalmente, desde $1955^{6}$ hasta los años 90; en ellos se obtienen procesos, normalmente convergentes, con valor dado de variación anual. La observación más detenida de los datos muestra subperiodos con procesos distintos. Algunos se detienen a principios de los años 90, mientras que otros llegan al siglo actual; la comparación entre los diferentes análisis se hace difícil por no existir coincidencias en el periodo de aplicación.

Son menos frecuentes las aportaciones que toman un periodo menor, de quince a veinticinco años. En ellos, el problema de las consideración de las CCAA como entes administrativos reales queda resuelto pero es precisamente en algunos de estos casos donde observamos unas conclusiones que pueden ser contradictorias.

6 La disponibilidad de datos, que comentamos en otro apartado, explica que muchos análisis partan precisamente de ese año, ya que en muchos casos se toma la serie de la renta nacional elaborada por el Servicio de estudios del Banco de Bilbao, que parte del ejercicio indicado. 


\subsection{Metodología}

$\mathrm{Al}$ ser el objetivo de este trabajo comprobar si existe convergencia o divergencia regional, la metodología aplicada en una gran parte de los textos revisados es muy parecida, aunque existen diferencias en cuanto a las variables empleadas y al período de tiempo considerado, así como al ámbito geográfico al que se aplica, tal y como ya se ha comentado.

Una primera aproximación a la existencia de convergencia o divergencia entre las regiones (o áreas económicas consideradas) consiste en analizar la evolución de los índices de concentración o dispersión de la variable que se considera relevante en cada caso. En este primer grupo de técnicas, lo más habitual en los trabajos revisados ha sido el cálculo de índices como, por ejemplo, el de Gini (que calibra el grado de equidistribución de una variable en relación, normalmente, con la población, a través de frecuencias acumuladas) ${ }^{8}$, o el de Theil (que mide el grado de desigualdad entre las diferentes regiones o áreas consideradas según la proporción que representa la variable a estudiar en cada región sobre el total) ${ }^{9}$. En los trabajos que se han revisado, las variables que se han analizado desde este punto de vista son muy variadas, pero pueden destacarse las que tradicionalmente se consideran como indicadores de la riqueza o producción (el PIB, el VAB, la renta o la renta disponible, generalmente en términos per capita).

Además del cálculo de índices mencionado, a partir de los postulados de los modelos de crecimiento neoclásico aplicados al ámbito regional, la principal metodología aplicada para estudiar la convergencia o divergencia ha consistido en determinar si se cumplían las hipótesis de convergencia desde dos puntos de vista: convergencia sigma (convergencia o) y convergencia beta (convergencia $\beta$ ), según la terminología acuñada por Sala tras su tesis doctoral.

7 Por razones de espacio, en este apartado realizamos una descripción muy breve de los diferentes enfoques metodológicos empleados en la mayor parte de los trabajos revisados, sin entrar en demasiados detalles acerca de los aspectos econométricos correspondientes a cada uno de ellos.

8 El valor 0 de este índice indica la máxima igualdad en la distribución y el valor 1 la máxima concentración.

9 En este índice el valor 0 indica la mínima desigualdad, correspondiendo la máxima al valor $\log N$ (siendo $\mathrm{N}$ el número de regiones). 
En el primer caso (convergencia sigma) se pretende contrastar si la evolución de la variable considerada (generalmente el valor añadido bruto por habitante o la renta por habitante) tiende a aproximarse en el tiempo en diferentes regiones o individuos; en otras palabras, se produce este tipo de convergencia si, en un grupo de economías, la dispersión de la renta real per capita (u otra variable en su caso) tiende a reducirse en el tiempo.

Por su parte, la existencia de la convergencia beta indica que las economías (países, regiones, etc.) más atrasadas tienden a crecer más rápidamente que las economías ricas, es decir, una situación de retraso relativo en un momento determinado tiende a reducirse con el tiempo; esto implica que hay una relación negativa entre la tasa de crecimiento de la renta per capita (u otra variable) durante un periodo y el nivel inicial de la misma y que se produce el denominado efecto caza (o catching-up).

Evidentemente, ambos tipos de convergencia están relacionados entre sí, aunque son diferentes y miden el mismo fenómeno desde dos perspectivas distintas y complementarias; puede probarse que, para que exista convergencia beta, es una condición necesaria, aunque no suficiente, la existencia de convergencia sigma ${ }^{10}$. En definitiva, la convergencia beta informa sobre la movilidad de la renta dentro de la distribución del conjunto de economías (regiones) analizadas, mientras que la convergencia sigma permite conocer la evolución de la dispersión de la renta.

Finalmente, en relación con la convergencia beta, puede distinguirse entre convergencia absoluta (o incondicional) y condicional (o condicionada). En la primera de ellas, se supone de forma implícita que las distintas regiones consideradas no presentan diferencias sustanciales en sus fundamentos económicos, encontrando una correlación parcial negativa entre crecimiento y renta inicial, es decir, las economías (regiones) más atrasadas tienden a crecer a una tasa mayor que las economías más ricas sin condicionarlo a ninguna característica de dichas regiones. En la segunda (convergencia beta condicionada), se parte de que las regiones tienen características heterogéneas, por lo tanto cada una de ellas tiende a converger hacia su propio estado estacionario (distinto del de las restantes) y sólo convergerán entre

10 A pesar de ello, hay algunos autores, como indican CUADRADO, MANCHA y GARRIDO (1998), p. 41, que discrepan de estos enfoques y consideran que la convergencia beta es irrelevante pues, en determinadas circunstancias, puede suceder que los datos muestren que hay convergencia, cuando en realidad se produce un fenómeno de polarización de la distribución. 
sí cuando sus características (variables condicionantes) sean similares ${ }^{11}$. Tanto en un caso como en otro, el denominado parámetro $\beta$ informa sobre la velocidad a la que se produce el proceso de convergencia, esto es, la tasa media anual a la que las economías van acortando su distancia relativa al estado estacionario ${ }^{12}$.

Como ya hemos indicado, la determinación de la convergencia beta y sigma es la metodología más empleada; ello no significa que todos los trabajos sean equivalentes, ya que, además del período o el ámbito espacial considerados, existe también una gran variabilidad en cuanto a la variable sobre la que se estudia la existencia de convergencia. Así, si bien, siguiendo a Sala, lo más habitual es realizar el análisis sobre la renta per capita u otra variable con un significado equivalente (como el VAB, la renta disponible o el producto, lógicamente también per capita), también es frecuente aplicar esta técnica al empleo, la productividad, la tasa de actividad o de paro y el volumen de capital.

Otro grupo de trabajos analizados (menos numeroso que el anterior), emplea el análisis shift-share como metodología explicativa de la existencia de un comportamiento diferencial de distintas variables en cada uno de los ámbitos geográficos estudiados (regiones, normalmente). La idea subyacente en este tipo de análisis consiste en descomponer la diferencia entre la evolución de una variable económica a nivel regional (empleo, producción, productividad, etc) y la evolución media o nacional de dicha variable, en dos componentes: el denominado efecto estructural, sectorial, proporcional o industry-mix (que recoge los distintos ritmos de crecimiento de los sectores productivos) y el conocido como efecto diferencial, regional comparado o competitivo (vinculado a las características propias de cada región, que originan que determinadas ramas productivas en dicha región tengan un crecimiento diferenciado). ${ }^{13}$

11 En la convergencia absoluta se realiza una regresión univariante entre el crecimiento de la renta y el valor de la renta inicial, obteniendo un coeficiente negativo para la renta inicial. Por su parte, en la convergencia condicional la regresión se realiza a partir de datos cruzados entre el crecimiento de la renta y su valor inicial, manteniendo constantes un cierto número de variables adicionales (variables condicionantes), y se llega también a que el coeficiente de la renta inicial es negativo.

12 Como comentamos en el apartado siguiente, en la mayor parte de los trabajos en los que se encuentra una evidencia empírica favorable al proceso de convergencia se obtiene para $\beta$ un valor de aproximadamente el $2 \%$ anual para las CCAA españolas.

13 A partir de esta idea general se han realizado varias modificaciones y la descomposición 
Este tipo de análisis ha sido objeto de numerosas críticas (que hacen referencia a su uso como herramienta para realizar predicciones, a los cambios en los resultados según el nivel de agregación, a la existencia de asimetrías y de correlación entre el efecto estructura y el diferencial), algunas de las cuales han llevado a su reformulación, lo que ha dado lugar a dos tipos de análisis shift-share distintos: el modelo convencional (que es el descrito en líneas generales más arriba) y el estocástico (el cual, mediante la óptica del análisis de la varianza, intenta paliar algunas de las críticas a las que se ha hecho referencia, en particular, la relativa a la interacción entre el efecto sectorial y regional).

Finalmente, también hay un cierto número de estudios que toman como perspectiva para analizar la dinámica regional y sus factores explicativos el análisis multivariante. Dentro del mismo, normalmente se ha recurrido al análisis de componentes principales, que, básicamente, reduce las variables iniciales que se consideran relevantes a un reducido número de ellas que explique una elevada proporción de la información de partida y que tengan una clara influencia sobre la variable a explicar. Un segundo paso, a partir de la información obtenida, se suele realizar a través del análisis cluster (o análisis de conglomerados), el cual permite la formación de grupos (conglomerados) integrados por regiones cuyas características son similares y que se diferencian claramente de los restantes (cada grupo se construye en función de la menor distancia de cada caso -comunidad autónoma- a un centro, de tal forma que se minimice la distancia de cada caso al centro de su grupo y se maximice la distancia entre los grupos; de esta forma los grupos son más homogéneos).

Un enfoque alternativo a los expuestos y que se emplea para otros aspectos (aunque también permite extraer conclusiones en términos de convergencia), es el análisis de la polarización, que intenta captar la medida en la que una población está agrupada en torno a polos distantes entre sí ${ }^{14}$.

Aunque ya se ha hecho referencia a las variables utilizadas normalmente en cada una de las técnicas comentadas, a modo de resumen, cabe destacar

resultante ha recibido distintas denominaciones, pero, en definitiva, la idea es la que se ha indicado: el crecimiento de una variable en una región se explica por la evolución nacional en todo el ámbito analizado y, además, por dos efectos adicionales: el que corresponde a los distintos sectores productivos y el relativo a cada región estudiada.

14 Véase al respecto el análisis efectuado por Esteban (1999), que aplica este concepto al examen de la distribución territorial de la renta (en el caso español, la distribución provincial). 
en relación con esta cuestión dos ideas importantes. La primera de ellas es la gran diversidad de variables que son susceptibles de ser analizadas bajo las diferentes metodologías, aunque, es cierto que hay algunas cuyo empleo es más frecuente: las que se suelen usar como indicadores del grado de bienestar de una zona o región, como el PIB, el VAB, la renta, la renta disponible, etc. ${ }^{15}$; también aparecen bastante las variables que hacen referencia a la dotación de factores productivos o a su empleo (la productividad, el nivel de capital -público, privado o total-, los gastos de inversión, la tasa de actividad, la tasa de paro o el nivel de empleo); finalmente, es menos habitual la construcción de indicadores o números índices a partir de un grupo de variables o el análisis de algunas de las variables indicadas anteriormente (como el VAB, el producto o el empleo) desagregadas por sectores productivos.

La segunda idea que cabe resaltar en relación con este tema surge precisamente a partir de la gran heterogeneidad a la que se acaba de hacer referencia. La causa de esta circunstancia se encuentra, por un lado, en la disponibilidad de los datos a los niveles deseados y en el período considerado; pero, por otro lado, también parece existir una cierta imprecisión (con excepciones) en el manejo de las variables, tomando los datos sin entrar en demasiadas profundidades acerca de su significado o la situación que pueden mostrar de forma exacta.

\section{Conclusiones}

Las conclusiones de los distintos trabajos son muy variadas e incluso, a veces, contradictorias. Muchos aspectos pueden justificarlo: distintos periodos temporales, diferencias respecto a la metodología, espacios no coincidentes, variables utilizadas diversas, etc. A pesar de todo, existen algunas conclusiones suficientemente contrastadas que permiten realizar algunas afirmaciones. A continuación se exponen agrupadas en dos epígrafes relativos, respectivamente, a las cuestiones de carácter más "técnico" y a los resultados obtenidos en relación con el proceso de convergencia.

15 Todas ellas suelen expresarse generalmente en términos per capita, aunque a veces se toman en valores absolutos y se considera también como variable a analizar la población. 


\subsection{Cuestiones técnicas}

Si nos centramos, en primer lugar, en las fuentes utilizadas, una cuestión, que no es meramente formal, se refiere al origen de los datos empleados. Casi todos los textos utilizan la información de la Fundación BBVA, puesto que es la única fuente que proporciona cifras para un largo periodo de tiempo. Existe una serie homogénea ${ }^{16}$ desde 1955 , lo que explica que éste sea el año del que parten muchas aplicaciones. Esta obra pionera de los estudios territoriales en España tiene algunos defectos puntuales, pero en conjunto ofrece unas series rigurosas y unas tendencias poco discutibles. Inicialmente, los datos se distribuían por provincias, aunque en fecha reciente aparecen ya cifras correspondientes a las CCAA. Esto plantea una dificultad de enfoque de los datos regionales que ya hemos comentado anteriormente. En fechas cercanas, se ha iniciado el estudio de variables por otras entidades (INE, FUNCAS) lo que ha permitido ampliar las fuentes de datos utilizadas, aunque insistimos en que para los años más lejanos hay que acudir necesariamente al BBVA (inicialmente Banco de Bilbao).

Otro tema que tampoco es secundario se refiere a las variables utilizadas para analizar si se produce o no convergencia. La que se emplea de forma más frecuente es la renta por habitante (o el VAB por persona, o el PIB per capita, e incluso la renta familiar disponible, también por persona; la definición de las variables es a veces poco clara, pero no entraremos en ello) ${ }^{17}$. En la mayor parte de estos casos, como veremos más adelante, se obtienen conclusiones que parecen confirmar la existencia de un proceso de convergencia entre las regiones.

En otros estudios, se analiza el comportamiento de otras variables, lo que trae consigo que las conclusiones obtenidas no siempre coincidan con las que acabamos de comentar. Así, la productividad por empleo lleva al mismo resultado: convergencia hasta el final de los setenta; incluso en algún caso el periodo convergente parece que es más importante medido a través de esta variable. Sin embargo, cuando se toman las cifras de empleo o los datos de paro lo normal es la divergencia; ello indica, quizás, que la movilidad del trabajo es mucho menos importante que lo que indican los modelos teóricos.

16 Banco de Bilbao (1978), Renta nacional de España y su distribución provincial. Serie homogénea 1955-1975, Bilbao, Ed. Banco de Bilbao

17 En algún escrito (J. Ś́nchEZ (1998)) se muestra que el empleo de variables per capita puede ser inadecuado. 
Como venimos insistiendo, nuestro objetivo de estudio son las CCAA, por lo que casi todo lo que hemos comentado en los párrafos anteriores se refiere a éstas. Sin embargo, algunos de los trabajos revisados aplican los modelos comentados en el epígrafe anterior a las provincias. En estos casos, aunque cambia el ámbito geográfico considerado, en general se podrían mantener las conclusiones comentadas más arriba en este nivel territorial de análisis, con una sola particularidad: la convergencia provincial, en su caso, aparece con menor unanimidad e incluso se observa alguna contradicción.

En parecidos términos, se concluye en algunos trabajos que existen grupos (que no coinciden siempre con las regiones) dentro de los cuales la convergencia se produce más claramente, mientras que las diferencias entre grupos se mantienen o se intensifican. Lo mismo se prueba en relación con las propias CCAA. Un aspecto cercano aparece en algunos estudios: la existencia de dos o más "clubes" de renta entre las CCAA.

\subsection{Resultados alcanzados en relación con la realidad del proceso de convergencia}

Como ya hemos adelantado en el epígrafe anterior, una primera conclusión de carácter general es que en los distintos estudios analizados hay bastante coincidencia en que aparece un proceso de convergencia, tanto entre las CCAA como entre las provincias españolas, hasta finales de los años setenta. A partir de estos años parece que la convergencia se debilita e incluso se hace negativa.

Durante los años ochenta y noventa, como hemos indicado, existen opiniones a veces contradictorias. Unas mantienen que la convergencia no desaparece y otras muestran una evolución divergente. No es posible llegar a conclusiones indiscutibles, pero sí se puede afirmar que la convergencia, si es que existe, ha sido mucho más débil que en los años anteriores.

Estas conclusiones proceden de los análisis empíricos que emplean los instrumentos convergencia sigma y convergencia beta. Estos métodos no pueden ir mucho más allá de las precisiones contenidas en el párrafo anterior. En general, los análisis distinguen la convergencia no condicionada de la condicionada; no vamos a entrar en este detalle ya que ello no modifica sustancialmente las conclusiones anteriores.

Como es natural, es importante detenerse en el valor del parámetro beta ( $\beta$ ) para subrayar la velocidad del proceso de convergencia. Aparecen mu- 
chas cifras distintas; con frecuencia el valor de beta es bastante elevado para el periodo que finaliza en 1979 aproximadamente. El dato del $2 \%$ que se determina en ciertos estudios lleva a la conclusión de que el proceso de acercamiento de las regiones españolas sería muy lento, lo que unido a los cambios estructurales podría perpetuar las diferencias entre las CCAA. De cualquier forma, el cambio aludido durante los años ochenta y noventa lleva a un cierto pesimismo sobre el equilibrio regional.

Como es evidente, hay estudios que utilizan otras técnicas o que las complementan con otros métodos, lo que permite matizar y enriquecer los planteamientos sobre convergencia. Todo esto lo tendremos en cuenta más adelante.

Cuando se compara el comportamiento de las CCAA españolas con las regiones europeas, es evidente que aparece un acercamiento claro a la media de la UE ${ }^{18}$. Esto no quiere decir necesariamente que haya convergencia entre las CCAA, lo único que indica es que el conjunto de la economía española converge con Europa, aunque ello puede ir unido a unas diferencias interregionales más intensas.

Finalmente, en los estudios que analizan el comportamiento de las regiones europeas (a veces se refieren a las regiones objetivo 1) se llega a ideas equivalentes. De forma muy esquemática: la convergencia de la renta por persona y la divergencia de la tasa de paro.

En muchos de estos originales se analizan, como ya hemos aludido, otros aspectos de interés, aunque no se refieran exactamente al tema que estamos estudiando. De todas estas ideas, parecen muy importantes las que se refieren a las características y causas del desarrollo o del subdesarrollo relativo en las regiones. Así, se insiste en que las desigualdades en la distribución de infraestructuras es una causa principal del subdesarrollo; sin embargo, también se señala que las inversiones empresariales son más importantes que las públicas en el crecimiento regional.

También el tamaño de las empresas, la densidad de la actividad económica y la cercanía a los centros económicos más importantes (y, por supuesto, la distancia al centro europeo) son factores que permiten o frenan el desarrollo. En este sentido existe una polarización en las grandes áreas metropolitanas

18 La convergencia con la media europea es muy clara en las regiones objetivo 1, incluso en el periodo 1994-2001 (véase Comisión Europea (2004)). 
que reduce el proceso de convergencia. Se ha repetido insistentemente que las diferencias de la productividad son un aspecto básico de las diferencias entre regiones; en otros términos, se señala la productividad total de los factores como la variable clave en este sentido; desde hace algún tiempo se insiste en que la aproximación tecnológica y la innovación tienen un papel central en estas diferencias.

Finalmente, la estructura productiva nos explica también el crecimiento; es evidente que la industria y los servicios aparecen como los principales sectores de las regiones más desarrolladas, en las que se han observado una reducción de la especialización en los años de convergencia.

\subsection{Un breve comentario final}

Como ya hemos comentado, una primera cuestión que es importante subrayar, es el hecho de que no existe coincidencia entre los resultados obtenidos por los trabajos examinados. En particular, para algunos años (especialmente a partir de los 80), en algunos casos se afirma que la convergencia no se produce, o ésta es muy débil, mientras que en otros se afirma lo contrario.

Por otro lado, de todo el estudio realizado, se deduce que la convergencia entre CCAA es un proceso que no es general en todas las épocas y que, en todo caso, no es tan importante como mantiene el modelo neoclásico. Esto nos lleva, por tanto, a señalar que la política pública tiene un papel, aunque sea modesto, en el equilibrio general.

Existen investigaciones y documentos que estudian esta política de las administraciones públicas que, sin embargo, no han sido objeto de nuestra revisión. Nos limitamos, por tanto, a recordar unas ideas bastante obvias que se contienen en los trabajos revisados: creación de infraestructuras para equilibrar los diferentes niveles de capital de las distintas CCAA; realización de inversiones públicas en salud y educación, ya que sus efectos sobre el desarrollo son positivos, mientras que las inversiones públicas productivas pueden incluso afectarle negativamente; y acciones dirigidas a aumentar la productividad del trabajo, especialmente en lo que se refiere a la difusión tecnológica. 


\section{Referencias bibliográficas}

Acosta, M. y CoRonado, D., (1998), "Disparidades regionales en los recursos y resultados empresariales de la I + D", en Anales de Economía (XII Reunión Asepelt España), Córdoba.

Aguayo, E., Expósito, P., Rodríguez, X. A. y VÁzquez, E., (1999), "La productividad como indicador de bienestar. Aplicación al caso de las comunidades autónomas españolas", en Anales de Economía Aplicada (XIII Reunión Asepelt España), Burgos.

AlCAIDE, J., (2003), Evolución económica de las regiones y provincias españolas en el siglo XX, Bilbao, Ed. Fundación BBVA.

AlCaide, J. y Alcaide, P., (2004), "Datos provisionales de la evolución de los agregados económicos en 2003 y avance del Balance Económico Regional. Años 1995 a 2003”, Cuadernos de Información Económica, nº 179, pp. 1 y siguientes.

Barro, R. J. y Sala, X., (1991), "Convergence across States and Regions", Brookings Papers on Economic Activity, nº 1, pp. 107-182.

Cancelo, M. T., Díaz, M. R., Guisan, M. C., (1998), "Gastos en investigación y su impacto sobre el crecimiento regional”, en Anales de Economía Aplicada (XII Reunión Asepelt España), Córdoba.

CARRASCO, E., (2001), "Análisis de las disparidades regionales en España”, en Anales de Economía Aplicada (XV Reunión Asepelt España), La Coruña.

CASTILlo, E. y SARABia, J. M., (1998), "Curvas de Lorenz de Pareto generalizadas. Aplicación al estudio de la desigualdad y la pobreza en España”, en Anales de Economía (XII Reunión Asepelt España), Córdoba.

COMIIÍ́ EUROPEA (2004), Una nueva asociación para la convergencia, competitividad, cooperación. Tercer informe sobre la cohesión económica y social, Luxwmburgo, Ed. Comunidades Europeas.

CuAdRADO, J. R., MANChA, T. y GaRRIDO, R., (1997), "La productividad regional en Europa: distintos patrones de comportamiento", en II Jornadas de Política Económica, Valladolid.

Cuadrado, J. R., (Dir.), Mancha, T. y GarRido, R., (1998), Convergencia regional de España. Hechos, tendencias y perspectivas, Madrid, Ed. Fundación Argentaria. 
CuADRADO, J. R., MANCha, T. y GARRIDO, R., (1998), “El crecimiento regional español (1980-1995): ¿es un fenómeno favorable a la convergencia real?, en XXIV Reunión de Estudios Regionales, Zaragoza.

Cuadrado, J. R., GarRido, R. y Mancha, T., (1999), "Disparidades regionales y convergencia en España. 1980-1995”, Revista de Estudios Regionales, $\mathrm{n}^{\mathrm{O}}$ 55, pp. 109-137.

Delgado, F. J., LóPez, A. J. y PÉRez, R., (1998), "Evolución de las regiones españolas en 1986-1996. El caso de Asturias", en Anales de Economía Aplicada (XII Reunión Asepelt España), Córdoba.

Delgado, M. y SÁnchez, J., (1998), "Las desigualdades territoriales en el estado español. 1955-1995”, Revista de Estudios Regionales, nº 51, pp. 61-89.

Dolado, J. J., González-Páramo J. M. y Roldán, J. M., (1994), "Convergencia económica entre las provincias españolas: evidencia empírica (1955-1989)", Moneda y crédito, $\mathrm{n}^{\circ}$ 198, pp. 81-131.

Domínguez, R. y GUJARRo, M., (2001), "Hacia una reconstrucción normativa del bienestar: evolución del índice físico de calidad de vida en España 1900-1960", Estudios de Economía Aplicada, nº 18, pp. 157-174.

EsPíNola, J. R. DE, (1998), "Inflación y desequilibrios interregionales en España (1980-1995)", en Anales de Economía Aplicada (XII Reunión Asepelt España), Córdoba.

Estavillo, J. A. y Zamora, M. M., (2001), "Análisis de productividad aparente del trabajo a nivel regional", en Anales de Economía Aplicada (XV Reunión Asepelt España), La Coruña.

Esteban, J. M., (1999 a), Un análisis de la polarización de la renta provincial en España, mimeo, Instituto de Análisis Económico, CSIC.

- (1999 b), "Un análisis de las desigualdades interregionales en Europa: la década de los ochenta", en Castells, A. y Bosch, N., (1999) Desequilibrios territoriales en España y Europa, Barcelona, Ed. Ariel.

Fajardo, M. A., SÁnchez, M. y Fajardo, M. A., (2004), “Dinámica del comportamiento económico de las regiones españolas y países de la Unión Europea, en el período 1980-1995", en Anales de Economía Aplicada (XVIII Reunión Asepelt España), León.

García, B., Raymond, J. L. y Villaverde, J., (1995), "La convergencia de las provincias españolas”, Papeles de Economía Española, nº 64, pp. 38-53. 
GARRIDO, R., (2002), Cambio estructural y desarrollo regional en España, Madrid, Ed. Pirámide.

GiL, C., (2001), Capital público y convergencia en las regiones europeas, Madrid, Ed. Civitas y Universidad Pública de Navarra.

Gil, C., PASCUAL, P. P. y RAPúN, M., (1998), "Eficiencia productiva y convergencia de las regiones españolas: un intento de cuantificación", en XXIV Reunión de Estudios Regionales, Zaragoza.

GoERLICH, F. J., (1999), “Dinámica de la distribución de la renta, 1955-1995: un enfoque desde la óptica de la desigualdad", Revista de Estudios Regionales, $\mathrm{n}^{\mathrm{o}} 53$, pp. $63-95$.

GoERlich, F. J. y MAS, M., (2001), La evolución económica de las provincias españolas (1955-1998). Volumen II. Desigualdad y convergencia, Bilbao, ed. Fundación BBVA.

González PÁramo, J. M. y Martínez, D., (2002), "Public investment and convergence in the Spanish Regions", en XXVIII Reunión de Estudios Regionales, Murcia.

HERRERA, J. y SANTAMARÍA, J., (2000), "La distribución del crecimiento económico en España 1955-1993”, Estudios de Economía Aplicada, nº 14, pp. 73-94.

LARRAZ, B., (2002), "Medida de la desigualdad de la distribución de la renta en la UE y en la UM", en Anales de Economía Aplicada (XVI Reunión Asepelt España), Madrid.

LASSO de LA Vega, M. C. y URRUTiA, A. M., (2002), "Analizando la estructura de la desigualdad de la renta en España”, en XXVIII Reunión de Estudios Regionales, Murcia.

LóPEZ, A. y CASTRo, R. B., (2003), "Dinámica de crecimiento de los ejes regionales en España: una perspectiva anual y regional", en Anales de Economía Aplicada (XVII Reunión Asepelt España), Almería.

MARTín, M., (1999), “Crecimiento y convergencia económica regional en España en el largo plazo”, Revista de Estudios Regionales, nº 54, pp. 47-65.

MÁs, M. y MAudos, J., (2003), "Infraestructuras y crecimiento regional en España diez años después", en XXIX Reunión de Estudios Regionales, Santander.

Más, M., Maudos, J., Pérez, F. y URiel, E., (1994), "Disparidades regionales y convergencia de las comunidades autónomas", Revista de Economía Aplicada, Vol. II, nº 4, pp. 129-148. 
MAYOR, M. Y LÓPEZ, A. J., (2003), "Dinámica regional del empleo: una aproximación basada en análisis shift-share estocástico", en Anales de Economía Aplicada (XVII Reunión Asepelt España), Almería.

Mella, J. M., (COORD.) (1998), Economía y política regional en España ante la Europa del siglo XXI, Madrid, Ed. Akal.

PEÑA, A. R., (1998), "Análisis regional de la especialización productiva española", en Anales de Economía Aplicada (XII Reunión Asepelt España), Córdoba.

Pérez, F., Goerlich, F. J. y MAS, M., (1996), Capitalización y crecimiento en España y sus regiones 1955-1995, Bilbao, Ed. Fundación BBV.

Rapún, M., EzcurRa, R., Gil, C. y Pascual, P., (2003), "Distribución espacial de la actividad económica: especialización y desigualdad en las regiones de la Unión Europea”, en XXIX Reunión de Estudios Regionales, Santander.

SALA, X., (1994), "La riqueza de las naciones. Evidencia y teorías sobre crecimiento regional y convergencia “, Moneda y crédito, $\mathrm{n}^{\mathrm{0}}$ 198, pp. 13-80.

- (1996), "Regional cohesion: evidence and theories of regional growth and convergence", European Economic Review, vol. 40, nº 6, pp. 1325-1352.

Salinas, J. y SAlinas, M. M., (1998), "Convergencia regional en el seno de la UE", en Anales de Economía Aplicada (XII Reunión Asepelt España), Córdoba.

Salinas, M. M. y Salinas, J., (1999), "Evidencia empírica sobre la movilidad y convergencia de las regiones europeas en el período 1981-1993", Estudios de Economía Aplicada, $\mathrm{n}^{\circ}$ 12, pp. 117-144.

SÁncheZ, J., (1998), "Disparidad y polarización de la producción provincial de España”, Revista de Estudios Regionales, º 50,pp. 81-108.

Toral, A., (1998), "El crecimiento económico regional en la Europa Mediterránea”, en Anales de Economía Aplicada (XII Reunión Asepelt España), Córdoba.

Villaverde, J. y SÁncheZ-Robles, B., (1998), "Disparidades provinciales y clubes de convergencia en España”, Revista de Estudios Regionales, no ${ }^{\circ}$ 2, pp. 177-199.

VILLAVERDE, J., (2004), "Convergencia provincial en España: un análisis espacial”, Papeles de Economía Española, nº 100 (vol. I), pp. 210-219. 